\title{
A Narrow Study on Two Forms of Wh-Question Concerning the Scope Ambiguity
}

\author{
Xinmeng $\mathrm{Hou}^{1, *}$ \\ ${ }^{1}$ College of Letter and Science, University of California, Los Angeles, Los Angeles, 90001, California, U.S. \\ ${ }^{*}$ Corresponding author. Email: dougur4magura@g.ucla.edu
}

\begin{abstract}
When talking about wh-movement, two basic forms will be considered. Languages with explicit wh-movement have syntactical form and logic form, whereas English has both forms. Other languages have varied mechanisms for posing constituents. For example, languages like Chinese and Japanese lack the wh-movement; wh-phrases remain their position in their surface structure. This article explores the differences in wh-question clarity regarding wh-situ-in and wh-movement and applies the scope principle. Chinese is chosen to be a subject language of wh-sui-in. English will be the language with both forms to be analyzed as the basal comparison object. It compares the ambiguous questions with wh-movement with the same question displaying wh-situ-in. And the quantifier category of wh-phrases, indefinite phrases, as well as adverb DOU will be discussed related to their syntactical connections with the subject.
\end{abstract}

Keywords: scope ambiguity, wh-situ-in, wh-movement, syntax sturcture, semantics.

\section{INTRODUCTION}

Scope ambiguity is usually defined as the meaning ambiguity resulting from the different qualifies to scope over each other. Qualifiers are the most common elements that involve sentence scoping in the surface representations of questions with explicit wh-movement. The position of a wh-phrase indicates which S-structure it belongs to. Some scholars argue that languages that do not contain the explicit syntactical movement of whphrases have the logical form of wh-movement. Scope principle applied in this paper will be the version brought up by Aoun and Li. The relative scope will not be taken regardless of the position in the chain. However, the scope principle is one of the assistances for determining the scope ranges. Questions of wh-situ-in do not always follow the anticipation from the syntactical scope principle. The deictic influencers command the specific part of speech of wh-phrases and semi-functional phrases semantically. The logic form of wh-movement and the scope principle will fail to resolve the meanings for many questions independently. Wh-situ-in fetches additional determiners such as interpretation of qualifiers and the phrase DOU in different but possible contexts.

\section{SCOPE AMBIGUITY IN QUESTIONS WITH WH-MOVEMENT}

This section will discuss how wh-phrases index other phrases and how it has the "narrow scope" in English. It will explore how the deep structures of sentences with embedded questions illustrate, how wh-movement occurs, and how the wh-phrases partition sentences regarding scope.

According to Katz and Postal, question types can be distinguished as yes-no question and wh-question [1]. The main distinctions are the question morpheme and particularly questioned elements. Baker indicates the " $Q$ [Question morpheme] may also occur clause-initially in embeddings, thus allowing Q-attraction (= WH movement) to be restricted to complement clauses." [2, 3]. In other words, the phrases to which Qs attach will be involved in the corresponding scope of wh-phrases. However, wh-phrases are not always appearing with wide scopes: "Only NPs (Noun Phrases) indexed to a matrix Q have a wide scope, i.e., only these NPs represent a direct request for information and are given a constant value in the declarative answer" [2]. For example, the wh-phrases from example (1), which is analyzed in (67): [S $\mathrm{S}_{1}$ Who remembers $\left[\mathrm{S}_{2}\right.$ where we brought which book?]

Above all, this question contains two S-structures; the broad structural analysis can be written as Analysis I. 
However, it is ambiguous without labeling the people with the behaviour of which book to bring. One possible interpretation can be that only the first wh-phrase "who" has a broad scope; the other possibility is both "who" and "where" has a broad range. If "who" alone has a wide scope, the meaning of the entire question is asking about the people attracted by "who" remember where we bought which book, shown as II. On the other hand, if both wh-phrases have broad scopes, the question will ask for every value assigned to "who" and "which book" III; therefore, it potentially contains multiple questions. The wh-phrase "Who" asks for different people with questions about the selling places of other books.

\section{Analysis:}

I. $\left[\mathrm{S}_{1}\right.$ Who [someone remembers $\left[\mathrm{S}_{2}\right.$ where [we bought which book at some place]]]].

II. $\left[\mathrm{S}_{1} \mathrm{Who}_{\mathrm{i}}\left[\right.\right.$ someonei remember $\left[\mathrm{S}_{2}\right.$ where $_{\mathrm{k}}[\mathrm{we}$ bought which book at someplace $\left.\left.\left.\left.{ }_{k}\right]\right]\right]\right]$

III. $\left[\mathrm{S}_{1} \mathrm{Who}_{\mathrm{i}}\left[\right.\right.$ someonei remember $\left[\mathrm{S}_{2}\right.$ where $[$ we bought which book at someplace $\left.\left.\left.\mathrm{k}_{\mathrm{k}}\right]\right]\right]$ ]

(possible answers: A remembers where we bought B at the bookstore.)

$\left[\mathrm{S}_{1} \mathrm{Who}_{\mathrm{j}}\right.$ [someonei remember $\left[\mathrm{S}_{2}\right.$ where [we bought which book at someplace $\left.\left.\left.\mathrm{k}_{\mathrm{k}}\right]\right]\right]$

(possible answer: $\mathrm{C}$ remembers where we bought $\mathrm{D}$ at the bookstore.)

However, similar ambiguity is not found in the question of wh-situ-in as Example 3:

\section{Example 1:}

Shui jide women zai nali mai-le shenme shu? Who remember we PRE where PST which book? 'Who remembers where we brought which book?' (Answer example: A remembers where we bought B. C remembers where we bought $\mathrm{D}$. etc.)

The common interpretation for this question is an interrogatory combination of three questions. The syntactical structure becomes less effective for questions with multiple wh-phrases, especially for wh-situ-in. Each wh-phrase directs one question for a different part of the answers. Answers that fill the wh-phrase with phrases of the expected part of speech are grammatical and perfectly match the question. This unambiguity is brought by equivalent focuses of three separate question phrases which are generated by equally incomplete sentence phrases without wh-phrases.

In conclusion, wh-movement with both forms does not prevent the scope ambiguity completely. Although wh-phrase with apparent syntactical movement brings solidity of single meanings in simple cases, it does not clear out the scope ambiguity caused by the inconstant meaning of NPs.

\section{SCOPE AMBIGUITY CONCERNING WH-SITU-IN QUESTION}

Wh-situ-in questions are questions containing interrogatory phrases in the identical position of being in a natural declarative sentence. As presented in the previous section, this declarative word order still works for questions with multiple wh-phrases. This identical feature cause issues for judging between interrogatory and declaratory. Wh-phrases in interrogatories are proved to be indefinite [4].

\section{1. scope ambiguity with qualifiers}

According to Cheng, it is still an issue whether whphrases in Mandarin Chinese undergo the logical form of wh-movement "since they do not have inherent quantification force" [4]. His argument about wh-phrases is contrary to what was mentioned in the research from Aoun, etc [5]. The other main contention is whether scope ambiguity is somehow caused by the other factors used among question phrases. Cheng's analysis of topicalization tends to explain that topicalizations would likely lead to wide scope reading of universal quantifiers [6]. For example:

\section{Example 2:}

mei-ge ren dou mai-le sheme? every-CL person DOU buy-ASP/PST what "What did everyone buy?"

a. 'What is the thing $\mathrm{x}$ such that everyone bought $\mathrm{x}$ ?' (scope of what $>$ scope of every)

b. 'For every $\mathrm{x}$, what is the thing $\mathrm{y}$ such that $\mathrm{x}$ bought $\mathrm{y}$ ?' (scope of every > scope of what)

(Possible Answer: Mary bought apples, Paul bought tomatoes, and etc.)

\section{Example 3:}

shei mai-le mei-yi-ben-shu?

who buy-ASP/PST each-one-CL-book?

'Who bought every book?

a. who is $\mathrm{x}$ such that $\mathrm{x}$ bought each book? (scope of who > scope of each book)

b. *For each y, y is a book, who is the one that bought $\mathrm{y}$ ? (*scope of each book $>$ scope of who)

Regarding to this distinct usage of "every", Cheng suggests that the reason for the discrepancy in the example has to do with divergent interpretations on merge ren (each-CL person) [4]. With salient content of a clarified group before every people, each will be read with a wide scope, for example:

Example 4:

Nimen

jia de mei-ge-ren dou mai-le sheme you-PL home DE every-CL-person DOU buy-APS what "What did everyone from your family buy?" 
Hsu argues that Isomorphic principle (IsoP) would be enough to explain the lack of scope ambiguity in some cases (such as Example 5), and scope ambiguity does exist. The IsoP demonstrates that QP(Question Phrase) in object position can only take a narrower scope than QP in subject position $[6,7]$. She takes the example of replacing wh-phrase such as "shenme" from Example 2 with indefinite NPs in object position:

\section{The IsoP or The Principle of Scope:}

Suppose A and B are quantifier phrases. Then if A ccommands B at S-Structure, A c-commands B at LF.

\section{Example 5:}

mei-ge-ren dou mai-le yi-ben-shu. every-CL-person DOU buy-ASP/PST one-CL-book a. * 'There is a book that everyone bought.' (*scope of $a>$ scope of every)

b. 'For every person $\mathrm{x}$, there is a book that $\mathrm{x}$ bought.' (scope of every $>$ scope of $a$ )

With multiple similar examples, Hsu concludes that "the subject mei-ge NP 'every NP' in each example ... has wider scope over the object indefinite NP" [6].

However, there is no apparent meaningful divergence for the listed example which is said to have multiple answers regarding a single sentence out from context. There are several controversial understandings of Example 2, because the meanings and parts of speech for DOU (means "all" in English when it functions as a meaningful word) were presumed differently, which results in divergence in interpreting this question. For instance, if DOU modifies the verb phrase as a universal quantifier $[8,9]$, the interpretation could be $(2 \mathrm{a})$ which asks for the same things brought by everyone. If DOU modifies the subject noun phrase, it fades the impression of "everyone" for the listeners and the question asks for all bought items. If DOU is treated as a function word or Scalar trigger [9] that does not address any features, the meaning will be (2b). Concerning the scope ambiguity, it is necessary to analyse the sentence without DOU. The intention for using the human classifier and talking about every person is to slice up a group of people into individuals. Therefore, a better glossing of mei-ge should be each of instead of every-one in Example 5.

\section{Example 6:}

mei-ge ren mai-le sheme?

Each-CL person buy-ASP/PST what?

"What did each person buy?"

a. * 'What is the thing $\mathrm{x}$ such that everyone bought $\mathrm{x}$ ?'

(scope of $w h>$ scope of Each)

b. 'For every $\mathrm{x}$, what is the thing $\mathrm{y}$ such that $\mathrm{x}$ bought

y?' (scope of Each $>$ scope of $w h$ )

\section{Example 7:}

ni-men mai-le shenme xiangtong-de?
You-pl buy-ASP/PST what same-adj.marker?

"What did you buy in common?"

Because the blinder of mei-ger-ren is usually implied in the context as the buying is not treated as universalized behaviour for all humans, Example 6 still appears ambiguous without the blinder. After adding a blinder, as in Example 7, the scope of wh-phrase shrinks and the scope of each expand; the question concerns each individual who conducted the action of buying. Furthermore, the usage frequency for the meaning of (6a) is much lower than (6b). Interpretation $6 \mathrm{a}$ is not completely impossible. It is deictically conceivable within a pre-designed and circumscribed context, as well as distinct intonation marks. But only talking about the syntax and its literal meaning, (6a) is unlikely to be achieved. Moreover, readers expect more detailed insentence description to ascertain the interpretation that is rare if there is no context involved which Example 6 does not provide.

Analyses from the previous section concern the nature of questions, regardless of any set-up contents that can be the same question substrates. And the meaning is likely to be the most common use of the sentence. But other meanings are also applicable with some premises such as intonation. Shen summarizes the findings of question in normal speech based on Changsha Chinese, "the intonation of questions in natural speech varies greatly and can differ even for the same syntactical structure" [10]. Intonations tie with discourse needs; although it is not the most important identification to classifying the question meanings, the variation with intonation in speech indicates the changes of context. Shen describes that the interrogation of plain questions that are unmarked morphologically, intonationally, and syntactically can only be perceived in the appropriate context [10]. Similar to the case of interpretation a in Example 2, high pitch on both DOU wh-phrase what will centralize the question emphasis to the questioned object. Therefore, the scope of what grows. Syntax structure is one of the factors determining the actual semantical outcomes in the question of wh-situ-in. And it also seems plausible that meaning-determining process is subjectively depending on the language using environment; in other words, elements of pragmatics can raise the issue for different interpretations. To determine whether there is scope ambiguity in simple questions, more evidence from actual practices is required.

\subsection{Scope ambiguity with multiple $S$-structures}

According to "Is There LF Wh-Movement?", the category of wh-situ-in is not in the inclusion relation with the logical form of wh-movement. Questions of wh-situin features are said to undergo a latent logical form of whmovement $[11,12]$. A null question operator (QU) that appears as the end word of some questions is treated as a quantificational element and is brought forward to satisfy 
the logical form, such as Example 8. Wh-phrase shenme is bound with QU so that ne asymmetrically c-commands mei-ge-ren [each-CL-person] and take it into its scope [5, 11]. But this null operator should not be regarded as a typical question operator that applies various questions. Above all, this operator does not exist as a question marker in most unambiguous questions; it functions as a mere modal particle mainly. Only when QU denotes assertive statements with interrogative tone does it serve as a question operator.

\section{Example 8:}

Mei-ge-ren mai-le shenme (ne)?

Each-CL-person buy-PST what (PART)

"What did each person buy?"

Depending on this alternative version of logical form, Shi (1994) argues that wh-phrases function as variables in questions rather than operators. "The V-Q compounds that give rise to A-not-A verbs in A-not-A questions are assumed to be raised at LF" (331). Complex questions containing more than one S-structure are considered to have two divergent meanings with [-WH] verbs such as Example 12. And the two interpretations will have different conditions of truth because of wh-phrase scoping. However, the existence of interrogatory interpretation is still mysterious because the critical condition for such a question does not rest on the feature of the verb. It is also possible for [-WH] verb to be in an interrogatory only sentence as shown in Example 13.

\section{Example 9:}

shui mai-le shu?

Who buy-ASP/PST book?

'who bought the book?'

\section{Example 10:}

Zhangsan zhidao [shei mai-le shu] [13].

Zhangsan know who buy-PST book

a. "Who does Zhangsan know bought books?

b. "Zhangsan knows who bought books."

\section{Example 11:}

$\mathrm{Ni}$ zhidao shei mai-le shu?

You know who buy-PST book?

"Who do you know that brought the book?

\section{Example 12:}

Zhangsan wen wo [shei mai-le shu].

Zhangsan asks me who buy-PST book

"Zhangsan asked me who bought books."

For example, the question alternative is impossible to be perceived unless a set-up context is included in deciding the pragmatic meaning. Both Example 12 and 14 have a trend for being complicated declarative sentences comparing with Example 13. The wh-phrase "shei (shui)" [who] is not a complementizer indeed due to the absence of wh-movement. It does appear to be a variable that is available for some meaning expansion. Wh-phrases can be pronouns that replace the unnecessary and uncertain information in the declarative sentence of Example 13. The component of "shei" does not change with regard to the meaning of verbs. There is no distinction on the interrogative complements of verb "wen" and "zhidao" as stated in Bersnan and Shi. It is common to have an interrogative sentence with "zhidao" without having declarative meaning divergence. Example 13 is an example that only has interrogative interpretation. Example 1 takes the transition and can be interpreted both ways. And Example 13 demonstrates an assertion statement that contains "who" as a definite phrase for referring to an unmentioned person. The main difference in the transition from interrogative interpretation to declarative interpretation is the informative degree of the first S-structure.

Furthermore, Example 12 includes a determiner "you" as the subject of the first S-structure which does not provide noticeable information, and therefore, it directs the focus to the beginning wh-phrase inside the second Sstructure and creates the interrogatory interpretation. If we focus on the segments before wh-phrase in Example 11, we will see it contains a noun phrase and an incomplete verb phrase; it does not have a complete sentence phrase before the who. This insufficiency for having sentence integrity contributes to the interrogatory option, but it does not conform to a definite interrogatory interpretation since who does not lead sentence as it does in Example 11. Referring to Example 10, there is also no extra modification on the subject replaced by what. Lastly, the complete sentence phrase without QNP inside the first S-structure (Zhangsan wen wo) of Example 13 is adequate to settle the declarative tone; this sentence has an equivalent focus on the two segments that can be separate before the wh-phrase. It is a declarative sentence by itself, but it is also grammatical to apply it as a question with appropriate context and intonation.

Therefore, the condition for questions displaying with wh-in-situ is addressing the wh-phrases and promote them as interrogatory makers. LF wh-movement does not diverge the interpretations towards an identical structure as QU is unnecessary for a sentence. The sentence attention denoted by innovation and context is significant and reliable comparing with the logical form and interrogatory feature of verbs.

\section{CONCLUSION}

This paper focuses on the scope ambiguity in question displaying wh-movement and wh-situ-in, respectively. English is the subject of wh-movement, and Mandarin Chinese is the subject of wh-situ-in. In general, both languages have scope reading issues regarding some whquestions. Questions with inconstant or indefinite NPs form after wh-movement is ambiguous. There are settled and persuasive analyses that explain this abstruse issue in English, but there are still a few controversial hypotheses for the ambiguity in Mandarin Chinese. The analyzed 
results show the nature of wh-question displaying whsitu-in is affected by multiple elements instead of solely syntax rules. But they are also available for other interpretations with particular innovations as well as appropriate context.

Furthermore, except for the existing hypotheses of wh-situ-in being an alternation of logical form whmovement, the informative or the complicated degree attached with sentence focus is also applicable to explain the distinctions of ambiguity for sentences with the same wh-phrase and in the same structures. Unbalanced quantities on the two sides of wh-phrases create the interrogatory interpretation. The factors of balance and sentence phrase completeness settle the interpretation literally. As shown in section 2.1, intonation and context are also abroad for meaning interpreting in dietic cases. Although these factors are more persuasive and practical in determining the question meanings, they do not conflict with the feasibility of syntactical analysis regards the logic form of wh-movement for some examples. Logic form of wh-movement is not the best answer to scope ambiguities in question displaying wh-situ-in.

\section{REFERENCES}

[1] Lyons, J. (1966). Jerrold J. Katz \& Paul M. Postal, An Integrated Theory of Linguistic Descriptions. (Research Monographs, 26.) Cambridge, Mass.: M.I.T. Press, 1964. Pp. xi 178. Journal of Linguistics, 2(1), 119-126. doi:10.1017/S0022226700001389

[2] Georgopoulos, C. (2013b). Syntactic Variables. Chapter 5, p.140-181, Springer Publishing.

[3] Baker, C. (1970). Notes on the Description of English Questions: The Role of an Abstract Question Morpheme. Foundations of Language, 6(2), 197-219. Retrieved July 25, 2021, from http://www.jstor.org/stable/25000451

[4] Cheng, L.-S Lisa (1991) On the Typology of Whquestions. Ph.D. Dissertation. Cambridge: MIT Press.

[5] Aoun, Joseph, and Yen-hui Audrey Li. 1993. Whelements in situ: Syntax or LF? Linguistic Inquiry 24:199-238.

[6] Hsu, Pei-Ling. Yumpu.com. (n.d.). scopeinteraction-in-mandarin-chinese. Retrieved August 4,2021,from,https://www.yumpu.com/en/document /view/52028589/scope-interaction-in-mandarinchinese

[7] Huang, C.-T James (1987) Existential Sentences in Chinese and (In)definiteness, In: Eric Reuland and Alice ter Meulen (eds.), The Representation of (In)definiteness. Cambridge: MIT Press. 226-253.
[8] Li, Yen-hui Audrey. 1992. Indefinite WH in Mandarin Chinese. Journal of East Asian Linguistics 1:125-156.

[9] Ying, Z. (2019). The Categorization of Dou (都) in Chinese: A Study from a Cross-linguistic Perspective, Bulletin of Chinese Linguistics, 10(2), 214-234. DOI: https://doi.org/10.1163/2405478X01002005

[10] Shen, X. (1991). Question intonation in natural speech: A study of Changsha Chinese. Journal of the International Phonetic Association, 21(1), 19-28. doi:10.1017/S0025100300005971

[11] Cole, P., \& Hermon, G. (1994). Is There LF WhMovement? Linguistic Inquiry, 25(2), 239-262. Retrieved August 4, 2021, from http://www.jstor.org/stable/4178860 Georgopoulos, C. (2013). Syntactic Variables. Springer Publishing.

[12] Chomsky, Noam (1973), "Conditions on Transformations", in Anderson and Kiparsky (ed.), A Festschrift for Morris Halle, New York: Holt, Rinehart \& Winston, pp. 232-286

[13] Shi, D. The nature of Chinese Wh-questions. Nat Lang Linguist Theory 12, 301-333 (1994). https://doi.org/10.1007/BF00993147. 